\title{
Presentación del dossier: los retos frente a la equidad, la justicia y el trato a las víctimas en el contexto político latinoamericano actual
}

\author{
Mary Luz Alzate Zuluaga* \\ Universidad Nacional de Colombia \\ Vera Rodrigues** \\ Universidade da Integração Internacional da Lusofonia Afro-Brasileira, Brasil \\ Laura Cecilia López ${ }^{* * * *}$ \\ Universidade do Vale do Rio dos Sinos, Brasil
}

\begin{abstract}
A los caminos de equidad y de un tratamiento igualitario de quienes se han visto histórica y sistemáticamente desatendidos y discriminados, por razones de su condición étnica, racial, social, de género en los países latinoamericanos, se le suma hoy en la región los retos por resolver las preguntas de las víctimas de las pasadas dictaduras, aquellas provenientes de las confrontaciones internas, o de las situaciones derivadas de las políticas sin ningún ajuste estructural y, como consecuencia, las restricciones de derechos.

Nos vemos abocados, a partir de este contexto político, a la reflexión por las implicaciones de los problemas pendientes de resolución nombrados por las propias víctimas, frente a las necesidades de reconstrucción de la memoria de los hechos y el reconocimiento e identificación de la sociedad amplia con el dolor sufrido. Lo que
\end{abstract}

\footnotetext{
*Doctora en Ciencias Políticas y Sociología por la Universidad Complutense de Madrid (Madrid, España). Profesora asociada en dedicación exclusiva del Departamento de Ciencias Políticas, Universidad Nacional de Colombia (Medellín, Colombia).Correo electrónico: mlalzatez@unal.edu.co iD) https://orcid.org/0000-0001-7173-3357

***octora en Antropología Social por la Universidade de São Paulo (São Paulo, Brasil). Profesora de la Universidade da Integração Internacional da Lusofonia Afro-Brasileira (Redenção, Brasil). Correo electrónico: vera.rodrigues@unilab.edu.br iD) https://orcid.org/0000-0002-0202-8010

*****actora en Antropología Social por la Universidade Federal do Rio Grande do Sul (Porto Alegre, Brasil). Profesora de la Universidade do Vale do Rio dos Sinos (São Leopoldo, Brasil). Correo electrónico: lauracl1975@gmail.com
} 
significa comprender y discutir con las víctimas como sujetos, que buscan ensanchar el sentido epistémico, normativo, cultural y práctico de la justicia, obligándonos a pensarnos como sociedad de manera vinculante con su dolor, de acuerdo a lo propuesto por Rancière (2010 [2003]), a sentirnos todos como "afectados" en el cuerpo de Otro.

Atendiendo a este planteamiento se ha propuesto este número monográfico. Buscamos establecer la relación de las víctimas con las decisiones gubernamentales, la construcción de la memoria y las demandas por justicia y las nociones de equidad e igualdad en clave no sólo de las políticas de Estado, sino también de las movilizaciones de los actores afectados por procesos de desigualdad.

Proponemos la apertura a las reflexiones que permitan la reconstrucción histórica, política e institucional de las distintas comisiones y procesos de paz vividos en décadas pasadas en Latinoamérica, a modo de sistematización de los aprendizajes como un legado experimentado. Análisis sobre políticas e iniciativas formativas construidas en escenarios de pos guerra, rupturas democráticas, desigualdad y que tienen la equidad y la justicia social como un horizonte común.

Las distintas situaciones que ordinariamente pueden generar opinión pública o movilización ciudadana se transforman espacial y temporalmente: los asuntos del pasado que causaron indignación, no son los mismos hoy. Los niveles de indignación pública varían en un mismo período de tiempo. Es decir, no se experimenta la misma afectación o sentimiento de injusticia por una problemática particular en todos los contextos políticos, culturales; ni son idénticos los asuntos que llaman la atención pública en el ámbito global con respecto al local o nacional, por más que hoy tengamos una mayor interacción transcultural y de interconexión virtual, lo que nos aboca a la relevancia de la pluralidad valorativa.

La escena pública de las movilizaciones ciudadanas de finales del siglo XX y comienzos del XXI ha ido variando en las demandas sociales y en las formas de expresión ciudadana. Esta variación ha dependido de la percepción del daño por parte de grupos sociales concretos, que han padecido, histórica y sistemáticamente, circunstancias de desigualdad y exclusión formal -ante la ley- y material - real ante la sociedad amplia-; así como la capacidad de presión social y política, para ampliar el sentimiento de daño o lesión sufrida por el grupo concreto, al resto de la población que no padece directamente la desigualdad o la discriminación.

El posicionamiento de sujetos políticos movilizados en torno a principios de igualdad y no discriminación se ha experimentado por diferentes vías, una de ellas, las llamadas acciones afirmativas. Este tipo de acciones se han enmarcado política y socialmente por varios discursos, dos de ellos: el legal/gubernamental y, el de las expresiones ciudadanas o de los grupos sociales directamente afectados. El análisis e interpretación de ese posicionamiento depende directamente del enfoque utilizado por los observadores. 
Los análisis e interpretaciones realizados han reabierto discusiones teóricas, tal como lo es el concepto de justicia, entrado el siglo XXI ha llevado a los estudiosos contemporáneos a plantear, desde las distintas demandas ciudadanas y las formas de hiperconexión virtual y física expresadas a lo largo del globo, que no estamos ante un único marco valorativo, ni ante un sólo modelo práctico de solución frente a lo común o los distintos problemas públicos compartidos en la sociedad actual. Por lo que autores, como es el caso de Fraser y Honneth (2006) plantean que una perspectiva crítica de la sociedad ya no puede apelar a un único horizonte compartido de valor. A su vez, son los actores sociales movilizados en protesta por la defensa o demanda de soluciones a problemáticas sociales, quienes nos aportan nuevas formas de ver y aceptar los patrones de valoración y actuación frente a lo justo y bueno en una sociedad.

De acuerdo al objetivo del dossier, en este número 14 se publicó en la sección dossier seis artículos que versan sobre la problemática de las víctimas y la idea de justicia. La edición abre con el artículo "'Pequeños triunfos': el impacto reparador de los juicios por crímenes de lesa humanidad en Argentina”, de Rosario Figari Layús, donde se analizan los efectos reparadores de los juicios penales por crímenes de lesa humanidad que se cometieron en Argentina durante 1970-1980 y la autora señala que la justicia puede tener un impacto significativo en la dignidad, los derechos y la calidad de vida de las víctimas. El siguiente texto es en coautoría, Luz Margarita Cardona Zuleta y César Augusto Londoño Álvarez, y se titula "La retórica del miedo como estrategia política. El plebiscito por la paz en Colombia”, los autores estudian los discursos de los líderes políticos de las campañas por el sí y por el no del Plebiscito por la paz en Colombia. Con esta investigación se identificó el uso de las emociones, de manera específica el miedo fue un elemento importante para que los electores tomaran la decisión de votar por el sí o por el no a los acuerdos de paz firmados en La Habana (Cuba), entre el gobierno de Colombia y de las Fuerzas Armadas Revolucionarias de Colombia (FARC).

De manera consecutiva, van a encontrar los artículos "Víctimas, la anulación de los sujetos", de José Luis Tejeda González, y "Valoraciones de la justicia y las acciones afirmativas. Reflexiones a partir de la firma de los acuerdos de paz de Colombia en 2016" autoría de Mary Luz Alzate Zuluaga. El primer contenido da cuenta del aumento de las víctimas, según el autor esto muestra la descomposición social que se vive en el mundo, además sugiere que es necesario identificar y enfrentar la problemática de las víctimas, dado que es indispensable para la recuperación social y política de las mismas y de la sociedad. Por otro lado, el segundo artículo muestra los cambios de los marcos valorativos de justicia y las acciones afirmativas, el texto se articula a través de la pregunta ¿Cómo se va ensanchando el horizonte de lo justo en la sociedad? Este interrogante se argumenta tomando el ejemplo del acuerdo de paz entre las FARC y el gobierno colombiano. 
Para cerrar la sección Dossier contamos con dos artículos, uno de ellos es de Yanina Guthmann, "Aportes conceptuales para el estudio micro político y social de organismos de Justicia en Argentina: el caso del Ministerio Público Fiscal (MPF)", que también estudia la justicia, pero en Argentina y cuyo objetivo es analizar el MPF no sólo como un organismo, sino también como éste permite conocer y analizar el concepto de políticas públicas de justicia y a su vez, tal como arguye la autora, contribuya a redefinir la dimensión estatal de la justicia. El otro texto se titula "Políticas públicas de memoria y contextos de transicionalidad: Colombia y Guatemala, 1996-2014” de Jonathan Piedrahita Usuga. El autor hace una revisión comparativa de las emergencias y alcances sociopolíticos de los discursos contenidos en las políticas públicas de memoria histórica y de búsqueda de la verdad en Colombia y Guatemala durante el período de 1996-2014.

En la sección Tema abierto se incluyeron el artículo "Extractivismo, conflictos ambientales y acción colectiva. Reflexiones desde la ecología política sobre el movimiento No a la minería en Urrao" de Hugo Cárdenas González y el texto "Las barras populares de fútbol y lo político en Colombia" autoría de Santiago Preciado Gallego. Uno de ellos analiza el movimiento social que se dio en Urrao (Antioquia, Colombia) en defensa del territorio a partir de la propuesta teórica de la ecología política. El artículo de Santiago Preciado tiene como marco conceptual la biopolítica y el biopoder de Michel Foucault para estudiar la relación entre las barras populares de fútbol y el poder político en Colombia.

El texto "Guerra Social Extendida o como la crueldad se adueña de todo" de Juan Diego Suárez Gómez lo encuentran en la sección Documento, es un contenido muy sugerente que nos invita a reflexionar sobre violencia social que se perpetúa en la sociedad colombiana y acerca del proceso políticos que enfrentamos, el acuerdo de paz que se firmó entre las FARC y el gobierno colombiano. Para cerrar el número se incluyó la reseña del libro Aniquilar la diferencia. Lesbianas, gays, bisexuales y transgeneristas en el marco del conflicto armado colombiano (2015), autoría de la reseña Giancarlos Delgado Huertas, este libro fue resultado de investigación del Centro Nacional de Memoria Histórica.

Los invitamos a leer este dossier que busca generar discusiones y reflexiones sobre nuestro acontecer político más inmediato y que además nos permite entender situaciones de violencia política y social que han sido nefastas para las sociedades latinoamericanas y que han afectado a millones de seres humanos, dándoles la condición de víctimas, discriminados, desplazados, presos políticos, migrantes, entre otros.

Los contenidos de la revista en la versión digital son de acceso abierto los pueden consultar y descargar en el siguiente vínculo https://revistas.unal.edu.co/index.php/forum. 


\section{Referencias}

Fraser, N. y Honneth, A. (2006). ¿Redistribución o reconocimiento? Madrid: Ediciones Morat. Rancière, J. (2010 [2003]). El maestro ignorante. Barcelona: Laertes editorial.

\section{Cómo citar}

Alzate Zuluaga, M. L., Rodrigues, V. y López, L. C. (2018). Presentación del dossier: los retos frente a la equidad, la justicia y el trato a las víctimas en el contexto político latinoamericano actual. FORUM. Revista Departamento Ciencia Política, 14, 7-11. 